\title{
Estratégias de comunicação na aprendizagem de português / espanhol por teletandem ${ }^{1}$
}

\section{Communication strategies for Portuguese / Spanish learning in-teletandem}

Andressa Carvalho Silva-Oyama*

UNESP

RESUMO: O contexto de interação de protótipo teletandem, por meio do aplicativo MSN Messenger, permite o intercâmbio de informação de linguagem em tempo real, pelo uso de voz, texto e imagens (webcam). Foi observado que, por se tratar de um ambiente de troca entre línguas próximas, alguns dos processos de aquisição demonstrados pelos aprendizes se assemelham. No entanto, a língua materna foi o fator de influência para particularidades em relação ao uso de estratégias de comunicação.

PALAVRAS-CHAVE: in-tandem, estratégias de comunicação, intra-interlíngua.

ABSTRACT: The context of interaction of the teletandem prototype, through the applicative MSN Messenger, allows an interchange of information about language in real time, by the use of voice, text and images (webcam). It was observed that, because it is an environment of exchange between related languages, some of the processes of acquisition demonstrated by the learners are similar to each other. However, the mother tongue was the trigger for particularities in the strategies of communication.

KEYWORDS: in-tandem, strategies of communication, intra-interlanguage.

\section{Introdução}

O avanço tecnológico e o consequente estreitamento de fronteiras são temas recorrentes quando o assunto é comunicação. As descobertas da ciência

\footnotetext{
${ }^{1} \mathrm{O}$ artigo apresenta parte dos resultados da pesquisa de Mestrado "O desenvolvimento intra-interlingüístico in-tandem a distância (português-espanhol)”, ano 2008, orientada pela Profa. Dra. Ana Mariza Benedetti.

* and_carsyl@yahoo.com.br
} 
ocorrem de maneira espantosamente rápida e são propagadas com ainda maior velocidade, dada a característica globalizada da sociedade atual. Desde o advento da Internet, vivencia-se a difusão em massa de computadores de mesa (desktops) e notebooks que, conectados à rede, interligam pessoas de vários lugares do mundo.

Assim, comunicações antes inviabilizadas por distâncias substanciais já podem ser estabelecidas facilmente por meio do conforto e das facilidades trazidas pela tecnologia. Claro é que nem todos têm o acesso a essas facilidades, por motivos sociais ou até mesmo políticos (países como China e Malásia, por exemplo, ainda impedem o uso da internet); entretanto, cabe aos cientistas, governantes e pesquisadores tentar viabilizar o cruzamento dessas fronteiras de impedimentos. O projeto "Teletandem Brasil - línguas estrangeiras para todos", ${ }^{2}$ em suas prescrições, com uso das comodidades que a tecnologia de informação (doravante TI) viabiliza, tem como respaldo motivacional um ideal social: viabilizar o acesso ao ensino intercultural de maneira virtual. A proposta é a de que, em um computador conectado à internet banda larga, o usuário acesse sua conta no $M S N$ Messenger, ${ }^{3}$ e, em horário previamente estipulado com um parceiro, falante da língua que está aprendendo, isto é, uma língua estrangeira (doravante LE), troque conhecimento mútua e reciprocamente, comunicando-se tanto por meio da escrita (chat) quanto oral e visualmente (microfone e webcam). Para isso, o projeto conta, no Brasil, com a disponibilização de máquinas em laboratórios próprios de Teletandem ${ }^{4}$ nas universidades participantes, e, com isso, dá-se o primeiro passo para a inserção social em rede.

Assim, além de responder às necessidades de não conformação com uma postura ainda passiva frente às novas tecnologias, o Teletandem Brasil também responde à necessidade de ambiente colaborativo para a aprendizagem, de contexto impulsionador de desenvolvimento linguístico, no qual há a oportunidade de travar interações significativas para a aprendizagem de LE. Por meio de uma agência central gerenciada por professores universitários, pares com interesses comuns são estabelecidos. Cada um deles ensina sua língua

${ }^{2}$ TELLES, J. A. Projeto Teletandem Brasil: Línguas estrangeiras para todos. Universidade Estadual Paulista, 2005. Disponível em: <http://www.assis.unesp.br/ departamentos/docs/TELETANDEM_BRASIL_completo.pdf>.

${ }^{3}$ Programa da Microsoft Corporation.

${ }^{4} \mathrm{O}$ projeto conta com o auxílio da agência de fomento FAPESP (Fundação de Amparo à Pesquisa do Estado de São Paulo). 
materna (doravante LM) e aprende a LM de seu interagente, ou seja, aprende uma Língua Estrangeira, interagindo em sessões regulares com temas previamente estabelecidos.

Desse modo, pares de diversas LEs são formados. Este estudo, entretanto, pode ser tido como investigador de línguas irmãs, uma vez que observa a aprendizagem de português brasileiro por uma argentina e a aprendizagem do espanhol rio-platense por uma brasileira no contexto de protótipo Teletandem. Cabe acrescentar que a pesquisa com foco nesses dois idiomas já rendeu muitas dissertações e teses (GONZÁLEZ, 1994; CRUZ, 2004) e, presentemente, também é escopo de vários trabalhos investigativos. Segundo Cruz (2004), a aprendizagem dessas LEs configura-se como uma aprendizagem diferenciada da de outros idiomas estrangeiros, devido à vasta proximidade entre essas línguas. Para Silveira (2001), quem as aprende e é falante nativo de sua congênere pode ser considerado como falso principiante, devido à grande interface de itens entre essas línguas. Falso principiante, diz a autora, para fazer menção à facilidade inicial (GONZÁLEZ, 1994) que os aprendizes desse idioma encontram para se compreender e se fazer entender, afirmação que será corroborada pelos dados e análise apresentados neste artigo.

Pensando sobre esse "falso começo", o artigo discorre sobre como se dá o uso de Estratégias de Comunicação (doravante $\mathrm{EsC}$ ) na aprendizagem colaborativa e cooperativa entre um par composto por uma aprendiz de espanhol como LE e uma aprendiz de português como LE no contexto de protótipo Teletandem (que, sob limitações contextuais, torna-se in-tandem a distância ${ }^{5}$ ), tendo como guia a seguinte indagação: quais são as Es $C$ utilizadas no contexto de protótipo Teletandem entre um par aprendiz de português / espanhol como LE?

Primeiramente, serão descritos os procedimentos metodológicos de coleta dos dados, os quais serão seguidos por uma breve fundamentação teórica. Na terceira parte, será apresentada a análise dos dados e, por fim, são expostas algumas considerações finais sobre o tema abordado no artigo.

\footnotetext{
${ }^{5}$ A proposta primeira era a de utilização dos recursos de imagem (webcam) e áudio. Entretanto, houve falta de isonomia de condições entre as participantes. A participante argentina não possuía computador e tinha que recorrer aos cybers, os quais não disponibilizavam todos os periféricos necessários à prática de Teletandem (microfone e câmera). As sessões ocorreram, em sua maioria, no gênero chat. Algumas delas (40\%) foram feitas com o recurso de áudio.
} 


\section{Metodologia}

O trabalho exposto neste artigo trata do estudo das interações entre um par tandem durante o período de seis meses. ${ }^{6}$ A proposta deste estudo é oriunda de um projeto maior: Teletandem Brasil - línguas estrangeiras para todos. Primeiramente, o projeto foi apresentado aos estudantes universitários de uma universidade pública do interior paulista. Os que manifestaram interesse receberam parceiros internacionais também dispostos a ensinar sua LM e a aprender a LM de seu par. O projeto adquiriu caráter institucional e grupos de aprendizes de diferentes LEs foram formados.

Elen, a interagente brasileira, possui computador domiciliar, assim como todos os periféricos necessários à interação. Por isso, realizou todas as interaçōes em sua residência. Lúcia, a interagente argentina, por sua vez, teve de recorrer aos cybers e pagar por hora o tempo de interação, uma vez que não possuía computador domiciliar nem institucional. Esse fato implica também a falta de isonomia de condiçôes aqui já mencionada, uma vez que nem sempre o computador disponível para Lúcia ${ }^{7}$ possuía todos os equipamentos necessários para a realização do protótipo Teletandem ou, quando havia os equipamentos, nem sempre estavam em boas condições de uso.

As interaçōes entre Elen e Lúcia ocorreram, em sua maioria, semanalmente, salvo um período no qual Lúcia mencionou dificuldades financeiras para poder interagir todas as semanas. Em horários previamente combinados, as interagentes conectavam-se à Internet, acionavam o aplicativo MSN Messenger e iniciavam a interação.

Como já mencionado, esse aplicativo permite o intercâmbio de informações de linguagem em tempo real, com o uso de recursos de voz (fala e escuta), de texto (escrita e leitura) e de imagem (webcam). Entretanto, devido a diversos entraves, somente foram possíveis algumas interaçôes com o recurso de áudio. Esse fato caracteriza a interação como in-tandem a distância, ou seja, como não totalmente prototípica de Teletandem.

Nos encontros on-line (uma hora para cada língua), as interagentes deveriam dedicar 30 minutos para conversação livre sobre temas previamente definidos, 20 minutos para oferecimento de feedback linguístico e 10 minutos finais para a avaliação da sessão. Entretanto, poucas vezes essa cronometragem

${ }^{6} \mathrm{O}$ presente artigo é parte do resultado de uma investigação de Mestrado, a qual foi denominada "O desenvolvimento intra-interlinguístico in-tandem a distância (português / espanhol).

${ }^{7}$ Elen e Lúcia são nomes fictícios empregados para preservar a identidade das interagentes. 
foi observada. As partes de cada sessão ocorreram em tempos díspares e somente algumas vezes todas as etapas da sessão Teletandem foram cumpridas.

A escolha dos instrumentos para esta investigação foi determinada pela coleta oriunda do projeto maior, Teletandem Brasil, e pelos objetivos gerais e específicos da presente pesquisa. Foram usados, como instrumentos de coleta de dados, questionários semiestruturados, autobiografias, gravações em áudio e em chat das interações in-tandem a distância, diários redigidos de modo a responder perguntas preestabelecidas, gravaçóes de mediaçoes realizadas entre a pesquisadora e Elen, inventário de EsC, entrevista final semiestruturada com Elen e Lúcia e um relato da experiência de aprendizagem in-tandem redigidos por Elen e por Lúcia.

Desse modo, foi possível detectar aspectos relacionados a expectativas e adaptação contextual, bem como o uso de estratégias e seu reconhecimento por parte das interagentes, o que fica explícito na exposição resumida da análise e discussão dos dados, disposta a seguir.

\section{Fundamentação teórica}

O conceito do Tandem foi desenvolvido em Bochum, no final da década de 60, na Alemanha. Desde seu início, havia uma organização em rede responsável pelo estabelecimento de parcerias tandems em uma agência central. $\mathrm{O}$ sistema tandem se diversifica com relação às maneiras pelas quais pode ser realizado. Isso porque, na literatura sobre o tema, encontram-se variados modos propostos para a prática de tandem, seja em relação ao meio pelo qual é feito, seja em relação ao número de línguas praticadas (quando os interagentes têm uma terceira língua em comum usada para resolver determinados problemas de comunicação, realiza-se o tandem trilingual) e até mesmo em relação à formalidade de sua aplicação (formal - aprendizagem alimentada e coordenada por um corpo educacional - e o tandem informal - espontânea e desenvolvida por indivíduos fora de um ambiente institucional) (PANICHI, 2002).

Em relação aos meios pelos quais o Tandem é estabelecido, tem-se o tandem face a face (realizado em encontros presenciais em bares, cafés ou ambientes propícios à troca) e o e-tandem, que, graças ao avanço da tecnologia, permite a comunicação entre duas pessoas de modo fácil e em ocorrências regulares por meio da troca de e-mails ou outras modalidades de comunicação, tais como telefone, videoconferência, fax, chat, SMS, carta etc.

Neste artigo, porém, contempla-se uma nova evolução do tandem, o Teletandem, que, como foi dito, utiliza recursos de chat, áudio e vídeo, perpassando o que seria o e-tandem, que se configura como o uso de somente 
uma modalidade de comunicação a distância, e diminuindo as distâncias para a realização do tandem face a face. Com isso, obtêm-se o êxito do estabelecimento de comunicação quase-presencial, ou, para usar o jargão da informática, comunicação virtual.

As interaçôes observadas deram-se tanto em áudio quanto em chat. Este é caracterizado como um gênero híbrido (CRYSTAL, 1996), uma vez que compartilha concomitantemente características da oralidade (velocidade de troca de mensagens, uso de marcadores conversacionais etc.) e da escrita, dado que o código é expresso de maneira registrada, patenteada por sinais gráficos.

Ressalta-se, que, em ambos os gêneros aqui observados, pode ocorrer a negociação de significado, a qual, segundo Long (1996), pode tornar o insumo qualitativamente diferenciado, pois, ao negociar significado, haveria maior compreensão do insumo dado e, consequentemente, maior qualidade do insumo como um fator influente na aquisição. Swain (1993), por sua vez, afirma que os alunos aprendem a falar "falando". A produção em LE forneceria oportunidades para uma prática linguística significativa, dado que os aprendizes necessitariam usar de seus recursos de modo a aumentar sua compreensibilidade, apropriabilidade e precisão na produção em LE.

Segundo Swain e Lapkin (1995), o uso de EsC provado pela literatura somente evidencia que os aprendizes são capazes de perceber, algumas vezes (grifo nosso), um problema em sua própria produção, mesmo sem receber feedback implícito ou explícito. Isso porque as EsC fazem parte do sistema intra-interlinguístico e de seu desenvolvimento, representando as dificuldades que o aprendiz tem ao se comunicar e os recursos dos quais lança mão para sanar suas lacunas comunicativas (MITCHELL; MYLES, 1998).

É justamente por se tratar de recursos que Faerch e Kasper (1983a, 1983b) defendem que há estratégias "com maior ou menor potencial de aprendizagem”. Os autores definem a aprendizagem de língua estrangeira como um processo no qual o aprendiz gradualmente desenvolve sua IL, à medida que formula hipóteses e as testa. A partir do momento em que tais hipóteses são lançadas para a atuação em uma comunicação real, pode-se obter um retorno (feedback) que será importante para que as hipóteses formuladas sejam incorporadas ou erradicadas da IL. Os autores, adotando um modelo relacionado ao comportamento intelectual, afirmam que as estratégias seriam funçóes relacionadas ao comportamento da IL, bem como ao seu desenvolvimento e à comunicação.

Já sobre a questão de definir se as estratégias são usos resultantes de planos conscientes ou não, defendem que são potencialmente conscientes. Isso 
porque salientam que não querem lançar à discussão o fato de os aprendizes serem conscientes ou não dos problemas que experienciam durante a comunicação, mas antes que aqueles que são conscientes disso podem criar melhores planos alternativos em outras situações e, por isso, podem desenvolverse de modo criativo e eficiente. Tarone (1983), por sua vez, mostra que é impossível afirmar se as EsC ocorrem em níveis conscientes ou não e, por isso, justifica evitar tratar sobre esse fator em sua definição.

Ademais, é problemático definir as estratégias como planos conscientes, uma vez que existem diferenças no grau de conscientização de processos mentais entre os indivíduos (SHARWOOD SMITH, 1979 apud FAERCH; KASPER, 1983). Há a necessidade de salientar que existem alguns planos que são sempre empregados conscientemente e outros que são esporadicamente. Por isso, Faerch e Kasper (op. cit.) preferem a categoria de planos potencialmente conscientes, isto é, que podem ou não sê-lo.

As estratégias de comunicação são, então, "planos potencialmente conscientes para resolver o que constitui um problema para o estudante que está tentando alcançar um objetivo comunicativo específico" ${ }^{8}$ (FAERCH; KASPER, 1983a, p. 36). Para os autores, os aprendizes podem resolver seus problemas por meio de comportamentos diversos. Os dois comportamentos principais seriam ou evitar o problema (quando tentam ficar longe do problema ou até mesmo mudar a sua meta comunicativa), ou tentar resolvê-los com um plano alternativo. Com base nessa distinção, diferenciam as estratégias de redução (que seria o evitar problemas) das estratégias de ativação (ativação da reflexão sobre o relacionamento entre problema, comportamento e estratégia).

Diversas taxonomias são encontradas na literatura, que, geralmente, propõem subdivisões para as estratégias baseadas em tentativas ou ativação do que se sabe, em ações de evitar o tópico e, por fim, para as tentativas de comunicar-se com a ajuda do outro (estratégias interacionais). Entretanto, ressalta-se que foram encontradas duas novas categorias no corpus de Teletandem (português / espanhol): ativação / compensação de Transferência de Gênero e a interativa de Pedido de Confirmação, as quais serão explicitadas na tabela de tipos de EsC resultante da análise exposta na subseção de "Análise dos dados".

\footnotetext{
${ }^{8}$ No original "...potentially conscious plans for solving what to an individual presents itself as a problem in reaching a particular communicative goal.”
} 


\section{Análise dos dados: o papel da LM no uso das EsC}

Em uma análise de cunho estatístico, é possível notar alguns pontos interessantes nos usos de EsC de Elen e de Lúcia. Para isso, observe-se, primeiramente, o gráfico que traz todas as EsC utilizadas por Elen em ambos os gêneros:

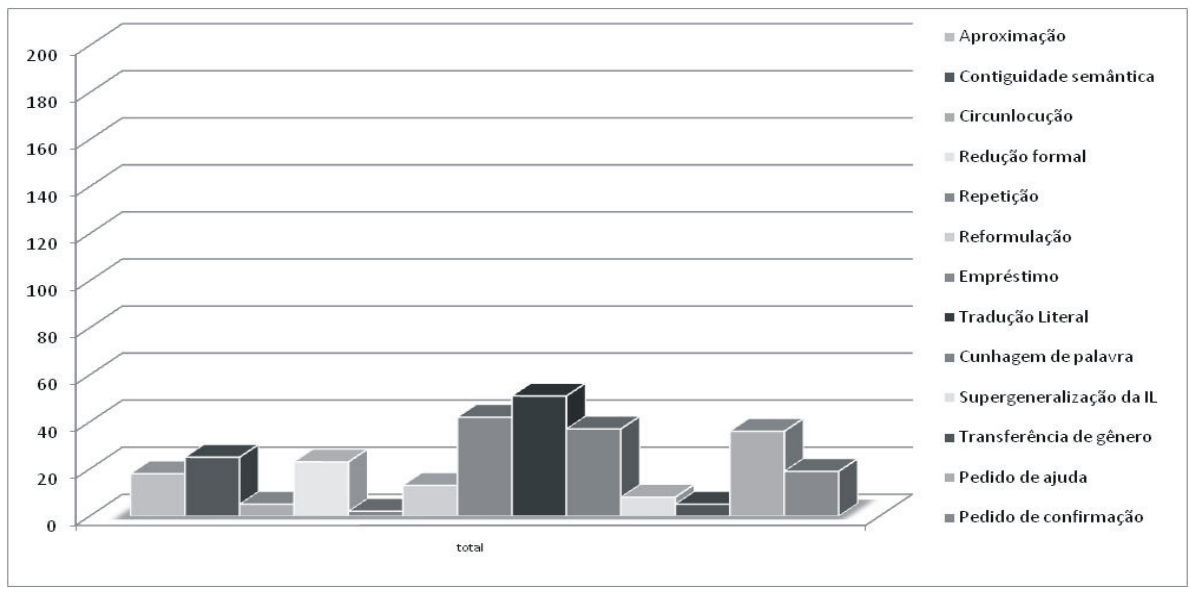

Elen usou, durante todas as interações, um total de 284 (duzentos e oitenta e quatro) EsC, distribuídas em 13 (treze) tipos de estratégias. A média de uso é, então, de 21,85 (vinte e um vírgula oitenta e cinco) e o desvio médio é de 12,75 (doze vírgula setenta e cinco) (vide TAB. 1 anexa).

Observe-se o esquema gráfico da totalidade de $\mathrm{EsC}_{\mathrm{C}}$ presentes na produção da interagente argentina:

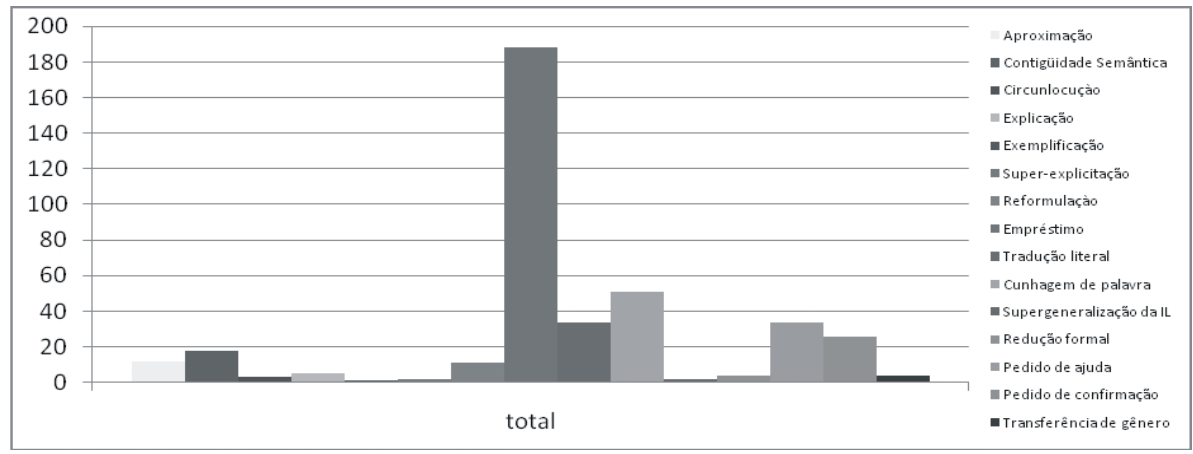


Lúcia usou, no total, 395 (trezentos e noventa e cinco) EsC, distribuídas em 15 (quinze) tipos. A média de uso foi de 26, 33 (vinte e seis vírgula trinta e três) e o desvio médio foi de 26,88 (vinte e seis vírgula oitenta e oito) (vide TAB. 2 anexa).

É possível observar que a média não é muito diferente em ambas as interagentes. Entretanto, o desvio padrão se difere imensamente. Esse fato mostra, então, que Elen parece ter o seu uso de $\mathrm{EsC}$ melhor distribuído, ou seja, que não se baseia somente em um tipo de Estratégia, mas que as usa em proporções mais igualitárias que Lúcia.

As EsC de ativação utilizadas por Elen tiveram a média do total de uso em 34,05 (trinta e quatro vírgula zero cinco). As EsC interacionais, por sua vez, tiveram uma média de 27,5 (vinte e sete vírgula cinco). Isso indica que há mais uso daquelas que dessas. Entretanto, ao olhar os mesmos dados na produção de Lúcia, nota-se que as EsC de ativação tem a média de usos total em 55,8 (cinquenta e cinco vírgula oito) e as $\mathrm{EsC}$ interacionais, 30 (trinta).

Esse dado explicita que Lúcia não é tão usuária de $\mathrm{EsC}$ interacionais quanto Elen. Esta, por sua vez, demonstra, no referido contexto, usar em proporções aproximadas (com uma diferença de 7 - sete - usos) as referidas EsC. Lúcia, por sua vez, usa muito mais as EsC de ativação, ou seja, estratégias baseadas na sua IL (FAERCH; KASPER, 1983), dado que a diferença entre usos é de 25,8 (vinte e cinco vírgula oito).

Olhando somente para o uso da EC de Empréstimo na produção de Lúcia, observa-se que desvia, em relação à média de usos, em 166,33 (cento e sessenta e seis vírgula trinta e três). Ou seja, esta estratégia foi, como mostra o gráfico, o recurso mais utilizado pela interagente argentina, podendo ser considerado até mesmo como um uso maciço dessas estratégias. Mas, como mostram as quantificações, na produção de ambas as interagentes foram mais recorrentes EsC de Ativação / Compensação no Código (KASPER; KELLERMAN, 1997). Esse dado pode ser resultado, dentre outras coisas, da diferenciada influência (facilitadora) que desempenha a LM no aprendizado de português por falantes de espanhol e vice-versa. Como afirma Cruz,

Observemos que no caso de línguas próximas (português / espanhol), as EsC estão presentes com muita intensidade, desde o início do contato com a língua-alvo. Após um primeiro movimento de aceitação da IL do aluno, com todas as EsC que ele utiliza, o professor deve despertar no aprendiz sua consciência sobre as diferenças, a visão 
contrastiva contínua, para que o aluno não fossilize pela facilidade da comunicação 9 (2004, p. 39).

Cruz (op. cit.) explicita, então, o quanto as EsC estão presentes na produção de aprendizes de línguas próximas. Isso provavelmente se deva ao fato da observação já constatada e, até mesmo "sancionada”, do grande número de transferências da LM para a LE, para não dizer interferência. ${ }^{10}$

Assim, é possível notar que algumas estratégias caracterizadas como conceituais pela literatura parecem, no contexto de interação analisado presentemente, vincular-se mais propriamente às $\mathrm{EsC}$ de Transferência e de Morfocriação. Entretanto, para postular tal asserção, primeiramente, é preciso observar a relação entre o uso de determinadas EsC e os desvios apontados pela literatura como sendo influenciados por processos transferência:

\begin{tabular}{l|l|l}
\hline $\begin{array}{l}\text { Taxonomia EC } \\
\text { (KASPER; } \\
\text { KELLERMAN, } \\
\text { op. cit.) }\end{array}$ & $\begin{array}{l}\text { Taxonomia de erros } \\
\text { (BENEDETTI, 2000; } \\
\text { LEDESMA, 2000; SANTOS } \\
\text { GARGALLO, 1993) }\end{array}$ & Ocorrências \\
\hline Empréstimo & Empréstimo literal & $\begin{array}{l}\text { L: tive uma semana um poco::(Interação 05/ } \\
08 / 2006)\end{array}$ \\
\hline $\begin{array}{l}\text { Cunhagem de } \\
\text { palavras }\end{array}$ & $\begin{array}{l}\text { Empréstimo Adaptado / } \\
\text { Transferência }\end{array}$ & $\begin{array}{l}\text { E: antes de empezarmos a hablar en portugués } \\
\text { podrías decirme (Interação de 19/08/2006) }\end{array}$ \\
\hline $\begin{array}{l}\text { Tradução literal } \\
\text { Supergeneral. }\end{array}$ & Tradução literal & $\begin{array}{l}\text { E: ¿estás me escuchando?(Interação de 19/08/ } \\
\text { 2006) }\end{array}$ \\
\hline da IL & Supergeneralização das regras & $\begin{array}{l}\text { Elen diz: no me lo entendias antes (interação } \\
\text { de 20/07/2006) }\end{array}$ \\
\hline $\begin{array}{l}\text { Contiguidade } \\
\text { Semântica }\end{array}$ & Semântica inapropriada & $\begin{array}{l}\text { Lúcia diz: por que es un adverbio de cantidad } \\
\text { Elen diz:si entiendo (interação de 20/07/2006) }\end{array}$ \\
\hline
\end{tabular}

${ }^{9}$ No original "Observemos que en el caso de lenguas próximas (portugués / español), las ECs están presentes con mucha intensidad, desde el inicio del contacto con la lengua meta. Tras un primero movimiento de aceptación de la IL del alumno, con todas las ECs que él utiliza, el profesor debe despertar en el aprendiz su conciencia sobre lo que hay de distinto, la visión contrastiva continua, para que el alumno no fosilice por la facilidad de la comunicación".

${ }^{10}$ Ressalta-se que não se trata do uso do termo interferência encontrado em Brown (1987) ou em Santos Gargallo (1993), que a denominam como "transferência negativa". No presente estudo, usa-se o termo tão somente para explicitar o escopo que os aprendizes dessas línguas têm em sua LM. 
A análise sobre as EsC de Contiguidade Semântica permitiu a observaçãoo de que as escolhas eram realizadas com respaldo na LM. Para a Análise de Erros, a maioria dessas ocorrências se configurava como um desvio da norma. Entretanto, com base nas informaçōes e observaçōes retiradas dos dados das interações in-tandem, foi possível observar que não se trata de um desvio, mas antes de um uso possível, porém não tão pragmático / comum, calcado em escolhas provenientes da influência da LM.

Ou seja, é possível constatar que na aprendizagem entre línguas próximas, então, há grande influência da LM. O acesso à LM se mostra ser constante na aprendizagem dessas línguas, mas, ressalta-se, representa somente uma das vertentes da transferência (GONZÁLEZ, 2005).

Assim, nota-se que o uso de algumas EsC de ativaçăo está, muitas vezes, ligado aos desvios classificados como Transferência, Empréstimos e outros. Todos esses fatores também parecem ser desencadeados pela proximidade entre as línguas aqui estudadas. Segundo Almeida Filho (2001), "esse 'quase falar', essa 'criação possível', essa facilidade enfim que o falante de Espanhol experimenta ao produzir a palavra, mostra uma outra face - $\mathrm{o}$ da facilidade enganosa e do conhecimento movediço" (p.15).

Tal facilidade parece ser desencadeadora do uso de construçóes ou de escolhas baseadas na transferência de conhecimento da LM para a LE. A transferência não se produz somente quando há diferenças entre as estruturas em questão, mas, ao contrário, nota-se grande recorrência desse fenômeno quando as estruturas são semelhantes (FERNÁNDEZ LÓPEZ, 1991, p. 15), o que ocorre em grande parte das estruturas e léxicos entre as línguas abordadas no presente artigo.

A grande interface entre as línguas demonstra, nos dados, ser um fator de extrema incidência no desenvolvimento de ambas as interagentes. Tanto que Lúcia, ao produzir em sua própria LM, estranhamente, parece usar Traduções Literais de sua LE:

1 L: sí te escucho mucho bien ahora

2 (...)

3 E: sí (++) pero / pero digo si hay algunas/ algunos/ algunas dudas de/ de

4 portugués que estás estudiando en el instituto alguna cosa que $(+)$ querés

5 saber podés mandar alguna mensaje quen si yo puedo $(+)$ voy a:: responderte

6 sí? (+) entendés?

7 L: sí mucho lindo (interação oral de 19 /08/2006). 
É importante destacar que Elen já havia questionado sobre o tópico gramatical uso de muy y mucho para Lúcia, que não o explicita no momento da interação, mas, ao final, no curto tempo de feedback, corrige explicitamente o desvio de Elen:

1 L: es muy:: cierto y no mucho cierto

2 E: sí muy cierto

3 L: muy cierto: (+) (interação oral de 19/08/2006).

Entretanto, como se observa, Lúcia, apesar de demonstrar reconhecer a imprecisão linguística na produção de sua parceira, oscila ao produzir dita estrutura inclusive em sua LM. Provavelmente, o fato se dê devido a uma possibilidade de que sua IIL esteja interferindo até mesmo em sua LM, dada a proximidade tipológica entre as línguas usadas na interação.

O uso de muy / mucho gerou diversos problemas, talvez devido à própria oscilação de insumo na produção de Lúcia, ora correto, ora com a presença de desvios. Elen, novamente então, pede para que Lúcia lhe explique o uso correto e Lúcia envia por e-mail uma explicação para Elen. A interagente argentina também se coloca à disposição para, na interação, solucionar as possíveis dúvidas de seu par:

1 Lúcia diz: CUAL ES TU DUDAA

2 Elen diz: utilizo mucho con sustantivo, pero no puedo utilizar con verbo

3 también

4 Elen diz: ?

5 Lúcia diz: $S I$

6 Elen diz: como...comió mucho, dormió mucho

7 Lúcia diz: $B I E N$

8 Lúcia diz: PERO EN ESE CASO VA DESPUES DEL VERBO

9 Elen diz: y el muy se utiliza delante de adverbios y adjetivos

10 Lúcia diz: $S I$

11 Elen diz: como...muy lejos, muy bonito, muy guapa, muy cerca

12 Lúcia diz: BIENNNN!!!!!

13 Lúcia diz: OTIMO (interação em chat de 16/09/2006).

Não é raro que essas ocorrências aconteçam entre falantes de línguas próximas. A literatura sobre o assunto aponta já algumas discussóes sobre tais fenômenos. Para Almeida Filho (2001), essa possível interferência da LE na LM, ou talvez da própria IIL na LM, é caracterizada como uma "percepção frequente e incômoda": 
Uma percepção freqüente (e incômoda) dos aprendentes hispânicos de Português é a de que estão falando ou escrevendo errado a própria língua ao tentar falar e escrever na língua-alvo nos primeiros estágios. Essa impressão transparece na prática comum entre falantes e aprendentes do Português e Espanhol da brincadeira de que "Português é Espanhol mal falado" e vice-versa. A representação da nova língua precisaria ser trabalhada pelos alunos com os seus professores se quiséssemos amenizar esses efeitos (p. 16).

Como o próprio autor salienta, há a necessidade de que a nova língua seja trabalhada de modo a levar à reflexão sobre o fenômeno já constatado da interferência (ou, segundo González, op. cit., transferência) que ocorre entre o português e o espanhol. Os dados sugerem que o uso de EsC pode ajudar nesse trabalho, pois, como será visto, permite que o parceiro mais competente possa mapear as dificuldades de seu companheiro e, assim, oferecer insumo que vá ao encontro das necessidades reais em LE. Observe-se o uso da EsC interacional de Pedidos de Confirmação:

1 Lúcia diz: panelas = olla

2 Lúcia diz: quero saber se esse é o signifacado

3 Elen diz: olla é aquela que tem pressão?

4 Lúcia diz: aqui todos se clamam igual

5 Elen diz: então está certo (interação em chat de 04/11/2006).

Lúcia, então, realiza um Pedido de Confirmação para saber se o correspondente para o léxico almejado estava correto. Em entrevista realizada com essa interagente, a pesquisadora buscou saber sobre a grande quantidade de Empréstimos utilizados. Lúcia admitiu que os realizava, mas com a intenção de pedir confirmação (o que configuraria, então, o uso de uma EsC interacional):

1 Pesquisadora diz: ¿Cómo lograbas comunicarte cuando no sabías o no

2 recordabas la palabra/ expresión en portugués?

3 LÚCIA diz: lo decia en español y le preguntaba a ella como se decia

4 Pesquisadora diz: ah, entonces preguntabas en tu lengua?

5 LÚCIA diz: no la pregunta la realizaba en portugués

6 LÚCIA diz: la palabra sola en español

7 Pesquisadora diz: pero decía la expresión o palabra en español a que ella te

8 dijera como era en portugués, ¿no es eso?

9 LÚCIA diz: por ejemplo, Como se diz "yeso" em português? (Entrevista final - janeiro de 2007). 
Ou seja, Lúcia afirma que os Empréstimos feitos eram para que o par pudesse fornecer-lhe um apropriado feedback, o que comprova, então, que se trata realmente de um uso estratégico, e não de um desvio linguístico somente.

Mas Elen e Lúcia, por meio da interação tandem, parecem ter desenvolvido consciência dos processos e do próprio progresso em desenvolvimento rumo a LE. Foram recorrentes os comentários realizados sobre as "dificuldades de separar a LM da LE". Elen até mesmo as intitulou como grande desafio:

1 acho que o nosso desafio é tentar separar a nossa língua da língua estrangeira,

2 sempre que for possível (Diário de interação oral de 05/08/2006).

A interagente parece reconhecer que a facilidade desencadeada pela proximidade entre as línguas oferece uma complexidade para interagir. Ao dizer que é necessário separar as línguas, provavelmente esteja se referindo à tentativa de utilizar o espanhol de maneira o mais distante possível de sua LM (português) o que, apesar de ser complexo, devido à grande interface entre as línguas, pode ser buscado por meio da interação in-tandem com um parceiro mais competente. $\mathrm{O}$ único diário produzido pela interagente Lúcia também reflete essa percepção:

1 En las dos interacciones que he tenido con ella he notado su evolución tanto en

2 la fonética como en su escrita, se encuentra más segura y un poco más relajada a

3 la hora de hablar.En la escrita tiene los mismos errores que yo, que es propio de

4 la interferencia de nuestra lengua materna, como ser la utilización de los

5 pronombres oblicuos y la conjugación de los verbos y en su caso el uso del

6 voceo (Diário de Lúcia - interação oral de 09/10/2006).

Esses dados sugerem, então, que inclusive as interagentes reconhecem que a transferência ou interferência da LM desempenha substancial papel em sua produção. Desse modo, é possível estabelecer um elo entre as EsC e a influência (ou, segundo as interagentes, interferência) da LM na produção em LE.

Essa conclusão permite afirmar, agora com respaldo também na voz das próprias interagentes, que a EsC de Contiguidade Semântica analisada nos dados parece também ser fruto de uma transferência da LM. A literatura a aponta como sendo conceitual (LITTLEMORE, 2001; KASPER; KELLERMAN, 1997), mas a análise dos dados in-tandem a distância permite enquadrá-la como uma subclasse de transferência / morfocriação.

A EsC de Redução Formal, por sua vez, também pode ser enquadrada, potencialmente, como sendo desencadeada pela influência da LM, no que tange 
à produção da interagente Elen. Isso porque não se trata de algo que foi pragmaticamente reduzido. $\mathrm{O}$ aprendiz também se arrisca e, com os recursos que têm à mão, tenta produzir em LE, com base, muitas vezes, em colocações opcionais de elementos sintáticos de sua LM (como o uso dos pronomes clíticos):

1 Elen diz: me mandaste para cual correo?

2 Lúcia diz: DE HOTMAIL

3 Elen diz: no consigo abrir $\emptyset$ (interação de 16/09/2006).

Como é possível observar, o uso dessa EsC não necessariamente implica a ocorrência de desvio linguístico. Entretanto, nesse caso, é perceptível que essa Redução Formal parece ser também causada em decorrência do levantamento de uma hipótese respaldada em conhecimentos advindos da LM, e, portanto, de uma transferência da LM. Já em relação à Lúcia, pode-se notar que sempre há a tentativa de produzir, mesmo sem os elementos necessários, o que pode ser considerado como Ativação, dado que não há abandono da mensagem (TARONE, 1983) nem evitamento do tópico (FAERCH; KASPER, 1983):

1 E: a: ta: $(++)$ então: aqui a gente se forma nas duas línguas: $(+)$ na língua

2 mater:na $(++)$ e na língua estrangeira

3 L: quanto ano (+) estuda: (+) espanhol?

4 E: quantos anos?

5 L: $\operatorname{sim}$

6 E: quatro anos (interação oral de 05/08/2006).

Por isso, essa EsC, no contexto, parece ser de uso tanto decorrente de $\mathrm{EsC}$ com base na IIL, e portanto, de transferência, quanto de somente uma não produção de elementos que não se tem certeza, sem entretanto, deixar de tentar comunicar a estrutura, o que a caracteriza como uma subcategoria de EsC de Ativação, dado que essa foi a característica observada quando de seu uso. Não se pode classificá-la diretamente como uma transferência, uma vez que somente Elen a usa, algumas vezes, com base na sintaxe da LM. Entretanto, no comportamento de Lúcia também se observa que há a tentativa de produzir, sem, portanto, fugir do tema ou abandonar a mensagem.

Portanto, com base na análise na produção de Elen e Lúcia e na proposta dos autores mencionados para taxonomias de $\mathrm{EsC}$, é possível chegar à taxonomia das $\mathrm{EsC}$ in-tandem a distância entre línguas próximas (português e espanhol): 


\begin{tabular}{|c|c|}
\hline Es $C$ & Definição \\
\hline \multicolumn{2}{|c|}{$\begin{array}{c}\text { Estratégias de ativação / compensação / recuperação-O aprendiz tenta resolver seu } \\
\text { problema comunicativo pela expansão de suas fontes comunicativas }\end{array}$} \\
\hline \multicolumn{2}{|r|}{ Conceitual } \\
\hline \multicolumn{2}{|l|}{ Holistica } \\
\hline Aproximação & $\begin{array}{l}\text { Uso de um item que compartilha algum aspecto semântico com } \\
\text { o item desejado, mas que não é o correto. }\end{array}$ \\
\hline \multicolumn{2}{|c|}{ Analiticas partitivas e lineares } \\
\hline Circunlocução & Descrição do que se tenta comunicar. \\
\hline Explicação & Explica-se as funçôes do item. \\
\hline Superexplicitação & Explicação longa sobre o item que se quer transmitir. \\
\hline Repetição & Produçāo repetida para objetivar a compreensāo. \\
\hline Reformulação & Reestrutura-se a oração ou item de modo a atingir o alvo comunicativo. \\
\hline \multicolumn{2}{|r|}{ No código } \\
\hline \multicolumn{2}{|c|}{ Transferência e Morfocriação } \\
\hline Empréstimo & Uso de um item lexical LM. \\
\hline Transferência de gênerd & Uso de um termo da LE com gênero da $L M$ \\
\hline Tradução Literal & O aprendiz traduz palavra por palavra para a $L 2$. \\
\hline Cunhagem de palavras & $\begin{array}{l}\text { Criação de uma nova palavra para comunicar o conceito } \\
\text { desejado, quando o aprendiz ignora o código em sua IIL. }\end{array}$ \\
\hline Supergeneraliz. da IIL & Combinação IIL e da LM - também nos niveis pragmáticos e discursivos. \\
\hline $\begin{array}{l}\text { Contiguidade } \\
\text { semântica }\end{array}$ & Uso de um item que é "vizinho" ao item que se objetivado \\
\hline
\end{tabular}

\section{Redução Formal}

\begin{tabular}{l|l}
\hline Redução Formal & Comunica-se significado por um sistema reduzido, sem determinadas
\end{tabular} estruturas, com base no apagamento de estruturas sintáticas de sua LM.

\section{Estratégias Interativas}

\begin{tabular}{l|l}
\hline Pedido de ajuda & O aprendiz pergunta pelo item ou estrutura desejado a seu par. \\
\hline Pedido de confirmação & $\begin{array}{l}\text { O aprendiz, após a tomada de risco, solicita a confirmação sobre } \\
\text { sua precisão ao par interagente. }\end{array}$ \\
\hline
\end{tabular} 
Como foi dito, as EsC acima mencionadas (de Redução e de Morfocriação) parecem estar relacionadas aos desvios encontrados na produção das interagentes, sejam eles essencialmente linguísticos ou essencialmente pragmáticos (como no caso da $\mathrm{EsC}$ de Contiguidade Semântica). Ou, olhando-se sob outro viés, tem-se que alguns dos desvios observados podem ser desencadeados pelo uso dessas EsC. Assim, fica exposto que nem todas as EsC podem ter relação com os desvios linguísticos, como já o afirmava Selinker (1972). Antes, o que se observa é que algumas EsC específicas parecem desencadear desvios linguísticos ou pragmáticos.

Faz-se o adendo de que essa relação não pode ser tida como axiomática, dado o fato de que o observador somente consegue contemplar as EsC que geram problemas na produção. Quando alguma delas é empregada e o aprendiz alcança sucesso, geralmente isso não chega aos olhos do pesquisador.

Ressalta-se, contudo, que tanto as EsC iconicamente esquematizadas quanto as demais estudadas e analisadas neste trabalho são importantes para que o par interagente possa oferecer um feedback adequado (o que configura o esclarecimento de dúvida como EC e como possível Estratégia de Aprendizagem). Desse modo, é de extrema relevância que o aprendiz se arrisque, dado o acordo mútuo de correção e tratamento dos problemas da ILL, pressupostos para a interação in-tandem.

Com base nos dados observados, foi possível considerar que diversos benefícios podem originar-se do uso de EsC. Lúcia utilizou-as e, apesar de têlas utilizado massivamente (EC Empréstimo), caso não houvesse tomado risco, não haveria exposto para sua parceira suas lacunas intra-interlinguísticas e, consequentemente, não haveria recebido nenhum feedback. $\mathrm{O}$ mesmo fato pode ser observado em relação a Elen: se não houvesse usado EsC, provavelmente não haveria apresentado o avanço constatado nos dados. Isso porque não haveria tomado risco e, consequentemente, não saberia se suas hipóteses estavam corretas.

Desse modo - e em conformidade com a postura de Faerch e Kasper (1983) -, o presente trabalho advoga que se deve ensinar aos aprendizes sobre procedimentos estratégicos de comunicação. Esse ensino, em primeiro lugar, tem a probabilidade de conscientizá-los sobre o singular papel dos desvios linguísticos: não se tratam de imperfeições, antes, de mostras de estágios de seu desenvolvimento. Ao cometê-los, o parceiro mais competente provê um feedback e o aprendiz, então, deve manipular o insumo à sua maneira (por isso a importância latente do concomitante ensino de EsC e de Estratégias de Aprendizagem, como advogam O'Malley e Chamot (1990)). 
Além do mais, o uso de EsC viabiliza a oportunidade de utilizar, de maneira prática, a língua que se está aprendendo. A afirmação de Swain (1993) de que o produzir força os aprendizes a estender sua competência ao limite também respalda essa postura. Os professores (ou pares mais competentes) devem estimular seu parceiro a tentar comunicar-se e a não evitar construçôes ou estruturas que não saiba. Antes, o aluno / interagente deve tentar conscientizar-se de que, em todo momento, arriscar-se é uma atitude que lhe dá grande probabilidade de desenvolvimento intra-interlinguístico. Evitar o risco, por sua vez, dificilmente lhe fornecerá oportunidades de aprendizagem em situação de comunicação.

Assim sendo, essa relação "dispararia" o desenvolvimento intrainterlinguístico com a presença de uma nova fase no ciclo: o feedback linguístico e / ou pragmático:

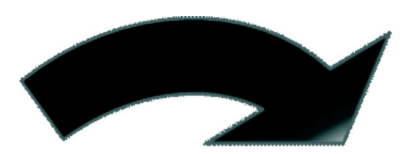

Desenvolvimentointrainterlinguistico

EsC e possivel desvio linguistico e/ou pragmático in-tandem a distância

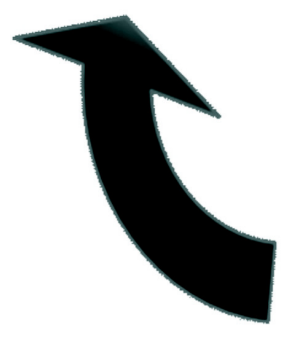

Feedback linguistico (EsA de mediação sociall EsC interativas)

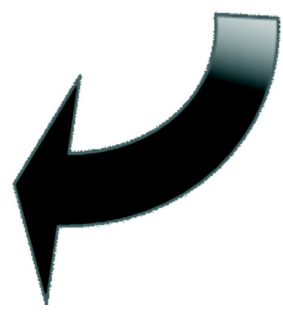


Ressalta-se que essa nova relação é hipotética, dado que o feedback tem o potencial de causar ou desencadear desenvolvimento intra-interlinguístico. E, como diversas variáveis estão presentes na aprendizagem (estilos individuais (FAERCH; KASPER, 1983; LITTLEMORE, 2001), afetividade e condiçóes psicológicas (KASHEN, 1982)), somente a criação de um aparato que captasse transformações neurológicas no momento do processamento e armazenamento do insumo na interação imediata seria capaz de demonstrar algo menos subjetivo mas, ainda assim, passível de subjetividade por meio da análise sob o viés de um analista.

\section{Considerações finais}

Foi possível observar, então, que o contexto de interação in-tandem a distância permite aos aprendizes travar uma experiência significativa de aprendizagem de LE, uma vez que há a oportunidade de interagir com um falante mais competente do idioma que se aprende. Nessa interação, aparecem as $\mathrm{EsC}$, as quais se prestam a resolver problemas ocasionados por lacunas de conhecimento intra-interlinguístico.

Foi possível observar que Elen, a interagente brasileira, usou menos tipos de $\mathrm{EsC}$ em proporções semelhantes (ou não tão díspares entre si). Diferentemente de Elen, Lúcia, apesar de ter feito uso de mais tipos de EsC, demonstrou procedimento estratégico mais recorrente o emprestar da LM o que não conhecia ou o que não acessava no momento de sua produção, o que desencadeou mais desvios, porém, concomitantemente, permitiu que Elen lhe oferecesse uma insumo mais direcionado e objetivo.

É importante destacar que a interação travada se pauta também no conhecimento mútuo das interagentes: ou seja, cada uma sabe que a outra possui conhecimento de ambas as línguas (LM e LE). Esse fato, aliado à proximidade entre os dois idiomas, parece ter tido um papel fundamental no uso das EsC passíveis de observação pelo pesquisador. Como já mencionado, quando o aprendiz usa uma EsC e obtém êxito, dificilmente esse dado chega aos olhos do investigador.

As EsC de Transferência de Gênero e de Pedido de Confirmação foram já levantadas quando de uma primeira categorização dos dados. As EC de Contiguidade Semântica, por sua vez, demonstrou ser peculiar no contexto, dado que as escolhas para uma semântica contígua tinham respaldo na LM. Assim, seu uso também pode ser considerado como um subtipo de transferência / morfocriação, e não como uma estratégia conceitual, que é 
caracterizada como o uso de referentes outros da LM para levar significado, tais como comparações ou uso de sinônimos (LITTLEMORE, 2001).

A EC de Redução Formal, por sua vez, não parece ter sido desencadeada por abandono da mensagem (TARONE, 1983) e nem por um evitamento (FAERCH; KASPER, 1983). Antes, também demonstraram ser resultantes de tentativas de ativar, de produzir em LE. Por esse motivo, foi classificada como um subtipo de EsC conceituais.

Como já se mencionou, os desvios - linguísticos ou pragmáticos encontrados se mostraram como sendo resultantes de estratégias de redução ou de transferência morfocriação. Ao se comparar da taxonomia de $\mathrm{EsC}$ com a de Análise de Erros, constata-se que muitos usos estratégicos podem encobrir problemas de acuidade linguística. Entretanto, como aponta Swain (1993), produzir em LE "força”" os aprendizes a se desenvolverem. Esse desenvolvimento, como ficou evidenciado nos dados, pode se dar por meio do uso de EsC (tentativas de comunicação com um sistema de IIL reduzido) e consequente feedback.

Por fim, é importante destacar o quanto o contexto de aprendizagem Teletandem é frutífero para que haja oportunidades de desenvolvimento de uma LE. Aprendizes que se engajam nessa experiência vivenciam um contexto intercultural telecoraborativo, que lhes permite atuar de modo autônomo e recíproco, preparando-os tanto para sua futura atividade profissional quanto para o desenvolvimento interpessoal. Isso porque há a necessidade de olhar o outro e respeitá-lo, bem como de cooperar de modo a criar uma atmosfera propícia à troca e ao desenvolvimento de ambos os sujeitos envolvidos.

O Projeto Teletandem Brasil (www.teletandembrasil.org) foi desenhado para tentar viabilizar essa esfera telecolaborativa, entretanto, tem-se ciência de que há um longo caminho a ser percorrido para que as oportunidades sejam oferecidas de maneira igualitária. Mas esse é justamente o propósito de um projeto de pesquisa pedagógico: ser desenvolvido de modo a encontrar os caminhos que encurtem as distâncias e que viabilizem o desenvolvimento e emancipação do sujeito aprendiz. 


\section{Referências}

ALMEIDA FILHO, J. C. P. de. Português para estrangeiros: interface com o espanhol. 2. ed. Campinas: Pontes, 2001.

BENEDETTI, A. M. Interferencias morfosintácticas y semánticas del portugués en el aprendizaje del español: identificación, predicción e incidencia de interferencias del portugués en la producción oral y escrita en lengua española de estudiantes universitarios del sur del Brasil. 1992. 347 f. Tese (Doutorado em Linguística Aplicada) - Universidade Complutense, Madrid, 1992.

. Interferencias semánticas del portugués en el aprendizaje del español. Formación de Formadores, v. 2, p. 9-24, 2001.

BROWN, H. D. Cognitive variations in language learning. In: of language learning and teaching. New Jersey: Prentice Hall, 1987. Principles BYALISTOK, E. Un modelo teórico del aprendizaje de lenguas segundas. In: LICERAS, J. M. La adquisición de lenguas extranjeras. Madrid: Visar, 1992, p. 177-92.

Some factors in the selection and implementation of communication strategies. In: FAERCH, C.; KASPER, G. Strategies in interlanguage communication. New York: Longman, 1993. p.100-18.

CORDER, P. Strategies of communication. In: FAERCH, C.; KASPER, G. Strategies in interlanguage communication. New York: Longman, 1983. p. 15-20. CRYSTAL, D. The Cambridge encyclopedia of the English language. Cambridge: Cambridge University Press, 1996.

CRUZ, M. L. O. B. Etapas de interlengua oral en estudiantes brasileños de español. Málaga: Ale Ele, 2004.

FAERCH, C.; KASPER, G. Plans and strategies in foreign language communication. In: . Strategies in interlanguage communication. New York: Longman, 1983a. p. 21-60.

. On identifying communication strategies in interlanguage production.

In: _____. Strategies in interlanguage communication. New York: Longman, 1983b. p. 210-38.

FERNÁNDEZ LÓPEZ, S. Análisis de errores e interlengua en el aprendizaje del español como lengua extranjera. Madrid: Edelsa, 1991.

FERREIRA, I. A. A interlíngua do falante de espanhol e o papel do professor: aceitação tácita ou ajuda para superá-la? In: ALMEIDA FILHO, J. C. P. de. Português para estrangeiros: interface com o espanhol. 2. ed. Campinas: Pontes, 2001. 
GONZÁLEZ, N. T. M. Cadê o pronome? - O gato comeu. Os pronomes pessoais na aquisição / aprendizagem do espanhol por brasileiros adultos. 1994. Tese (Doutorado em Lingüística Aplicada), Universidade de São Paulo, São Paulo, 1994. GONZÁLEZ, N. T. M. Quantas caras tem a transferência? Os clíticos no processo de aquisição / aprendizagem do Espanhol / Língua Estrangeira. In: BRUNO, F. C. (Org.). Ensino e aprendizagem de linguas estrangeiras: reflexão e prática. São Carlos: Claraluz, 2005. p. 53-70.

KASPER, G.; KELLERMAN, E. (Ed.). Communication Strategies: psycholinguistic and sociolinguistic perspectives. London: Longman, 1997.

KRASHEN, S. Principles and practice in second language acquisition. Englewood Cliffs: Prentice-Hall International English Language Teaching, 1982.

LICERAS, J. M. Hacia un modelo de análisis de la interlengua. In: La adquisición de lenguas extranjeras. Madrid: Arco Libros, 2000.

LITTLEMORE, J. An empirical study of the relationship between cognitive style and the use of communication strategy. Applied Linguistics. v. 22, n. 2, p. 241-65, Jun. 2001.

LONG, M. Native speaker / non native speaker conversation in second language interaction. In: M. Clarke; J. Handscombe (Ed.). TESOL'82: Pacific perspectives on language and teaching. Washington DC: TESOL, 1983.

LONG, M. The role of the linguistic environment is second language acquisition. In: RITCHIE, W. C.; BATHIA, T. K. (Ed.). Handbook of second language acquisition. New York: Academic Press, 1996. p. 413-68.

MITCHELL, R.; MYLES, F. Second language learning theories. London: Arnold, 1998.

O'MALEY, J.; CHAMOT, A. Learning strategies in second language acquisition. Cambridge: Cambridge University Press, 1990.

OXFORD, R.; SCARCELLA, R.C. The tapestry of language learning: the individual in the communicative classroom. Massachusetts: Heinle \& Heinle, 1992.

PANICHI, L. Tandem learning and language awareness. Materials from the ALA Tandem Workshop, 2002, não paginado.

SANTOS GARGALLO, I. S. Análisis Contrastivo, Análisis de Errores e Interlengua en el marco de la Linguistica Contrastiva. Madrid: Editorial Síntesis S.A., 1993. SCHWIENHORST, K. Co-constructing learning environments and learner identities- language learning in virtual reality. In: Proceedings of the ED-Medial ED-Telecom, Freiburg, 1998. 
SELINKER, L. Interlanguage. IRAL, v. 10, n. 3, 209-231, 1972.

SHARWOOD SMITH, M. Strategies, language transfer and the simulation of the second language learner's mental operations. Language Learning, v. 29, n. 2 , p. 345-362, 1979.

SILVA, A. C. O desenvolvimento intra-interlingüistico in-tandem a distância (português e espanhol). 2008. 357 f. Dissertação (Mestrado em Estudos Linguísticos) - Instituto de Biociências, Letras e Ciências Exatas, Universidade Estadual Paulista, São José do Rio Preto, 2008.

SILVEIRA, R. C. P. da. Português língua estrangeira. São Paulo: Cortez, 2001.

SWAIN, M. The Output Hypothesis: Just Speaking and Writing Aren't Enough. The Canadian Modern Language Review, v. 50, n. 1, p. 158-164, 1993.

SWAIN, M.; LAPKIN, S. Problems in output and the cognitive process they generate: a step towards second language learning. Applied Linguistics, v. 16, p. 370-391, 1995.

TARONE, E. Some thoughts on the notion of communications strategy. In: FAERCH, C.; KASPER, G. Strategies in interlanguage communication. New York: Longman, 1983. p. 61-74.

TARONE, E.; COHEN, A. D.; DUMAS, G. A closer look at some interlanguage terminology: a framework for communication strategies. In: FAERCH, C.; KASPER, G. Strategies in interlanguage communication. New York: Longman, 1983. p. 4-14. 


\section{Anexos}

TABELA 1

EsC Elen

\begin{tabular}{lcccc}
\hline EsC & Total & Média & Porcentagem & Desvio da média \\
\hline Aproximação & 18 & 0,947 & $6,3 \%$ & 3,85 \\
Contiguidade semântica & 25 & 1,316 & $8,8 \%$ & 3,15 \\
Circunlocução & 5 & 0,263 & $1,8 \%$ & 16,85 \\
Redução formal & 23 & 1,211 & $8,1 \%$ & 1,15 \\
Repetição & 2 & 0,105 & $0,7 \%$ & 19,85 \\
Reformulação & 13 & 0,684 & $4,6 \%$ & 8,85 \\
Empréstimo & 42 & 2,211 & $14,8 \%$ & 20,15 \\
Tradução Literal & 51 & 2,684 & $18,0 \%$ & 29,15 \\
Cunhagem de palavra & 37 & 1,947 & $13,0 \%$ & 15,15 \\
Supergeneralização da IIL & 8 & 0,421 & $2,8 \%$ & 13,85 \\
Transferência de gênero & 5 & 0,263 & $1,8 \%$ & 16,85 \\
Pedido de ajuda & 36 & 1,895 & $12,7 \%$ & 14,15 \\
Pedido de confirmação & 19 & 1,000 & $6,7 \%$ & 2,85 \\
\hline
\end{tabular}

TABELA 2

EsC Lúcia

\begin{tabular}{lcccc}
\hline EsC & Total & Média & Porcentagem & Desvio da média \\
\hline Aproximação & 12 & 0,632 & $3,0 \%$ & 14,33 \\
\hline Contiguidade Semântica & 18 & 0,947 & $4,6 \%$ & 8,33 \\
\hline Circunlocução & 3 & 0,158 & $0,8 \%$ & 23,33 \\
\hline Explicação & 5 & 0,263 & $1,3 \%$ & 21,33 \\
\hline Exemplificação & 1 & 0,053 & $0,3 \%$ & 25,33 \\
\hline Superexplicitação & 2 & 0,105 & $0,5 \%$ & 24,33 \\
Reformulação & 11 & 0,579 & $2,8 \%$ & 15,33 \\
\hline Empréstimo & 188 & 9,895 & $47,6 \%$ & 161,67 \\
Tradução literal & 34 & 1,789 & $8,6 \%$ & 7,67 \\
\hline Cunhagemde palavra & 51 & 2,684 & $12,9 \%$ & 24,67 \\
Supergeneralização da IL & 2 & 0,105 & $0,5 \%$ & 24,33 \\
\hline Redução formal & 4 & 0,211 & $1,0 \%$ & 22,33 \\
\hline Pedido de ajuda & 34 & 1,789 & $8,6 \%$ & 7,67 \\
\hline Pedido de confirmação & 26 & 1,368 & $6,6 \%$ & 0,33 \\
\hline Transferência de gênero & 4 & 0,211 & $1,0 \%$ & 22,33 \\
\hline
\end{tabular}

Recebido em 23/04/09. Aprovado em 14/08/09. 